\title{
Kinetic Modeling and Adequacy of Dialysis
}

\author{
Malgorzata Debowska ${ }^{1}$, Bengt Lindholm ${ }^{2}$ and Jacek Waniewski ${ }^{1}$ \\ ${ }^{1}$ Institute of Biocybernetics and Biomedical Engineering, \\ Polish Academy of Sciences, Warsaw, \\ ${ }^{2}$ Divisions of Baxter Novum and Renal Medicine, Karolinska Institutet, Stockholm, \\ 1Poland \\ ${ }^{2}$ Sweden
}

\section{Introduction}

The mathematical description of hemodialysis (HD) includes two parts: 1) explanation of the exchange between patient's blood and dialysate fluid across a semipermeable membrane of the dialyzer, and 2) characterization of the solute removal from the patient. The solute transport across the dialyzer membrane depends on the difference in hydrostatic pressure and solute concentration gradients between both sides of the membrane and also on the permeability of the membrane to the solute. The local equations for solute and fluid transport through the membrane are based on a phenomenological (thermodynamic) description according to the Staverman-Kedem-Katchalsky-Spiegler approach (Staverman, 1951; Kedem \& Katchalsky, 1958; Katchalsky \& Curran, 1965; Spiegler \& Kedem, 1966). The two compartment model describes the functioning of the patient - dialyzer system, assuming that body fluid is divided into two parts: one directly (extracellular compartment) and one indirectly (intracellular compartment) accessible for dialysis (Schneditz \& Daugirdas, 2001). The one compartment model of the solute distribution volume assumes that the solute is distributed in a single, homogenous pool. Solute kinetic modeling is based on a set of ordinary differential equations describing the changes of solute mass, concentration and distribution volume in body compartments and in the dialyzer. Using solute kinetic modeling one is able to evaluate dialysis efficiency.

The question concerning dialysis dosing has been debated and remains controversial since the beginning of the dialysis treatment era. Between 1976 and 1981, the National Cooperative Dialysis Study (NCDS) was performed in the United States to establish objective, quantitative criteria for the adequate dose of dialysis (Gotch \& Sargent, 1985; Sargent \& Gotch, 1989; Locatelli et al., 2005). The primary analysis showed that morbidity was less at lower levels of time average urea concentration. The secondary 'mechanistic' analysis of the NCDS data done by Gotch and Sargent launched the issue of urea KT/V (Gotch \& Sargent, 1985).

Single-pool KT/V overestimates the removed amount of urea because of the postdialysis urea rebound, i.e., a fast postdialysis increase in urea concentration in plasma, which is a compartmental effect; therefore, the equilibrated KT/V (eqKT/V), estimated by the Daugirdas formula, was introduced to clinical practice (Daugirdas et al., 2001). Equilibrated $\mathrm{KT} / \mathrm{V}$ values can be also calculated using an alternative equation by Daugirdas and 
Schneditz (Daugirdas \& Schneditz, 1995), or the formula derived from observations during the HEMO Study (Depner et al., 1999; Eknoyan et al., 2002; Daugirdas et al., 2004), or that introduced by Tattersall et al. (Tattersall et al., 1996).

The usage of the KT/V index as a sole and optimal measure of dialysis dose is questioned by many authors. Fractional solute removal (FSR) and equivalent continuous clearance (ECC) are two such alternative options, which can be used instead of KT/V. FSR was suggested by Verrina et al. (Verrina et al., 1998) and Henderson (Henderson, 1999) for comparative studies of various dialysis modalities and schedules. By definition FSR is the removed mass over the reference solute mass in the body. The concept of FSR is closely related to the concept of the solute removal index (SRI) proposed by Keshaviah (Keshaviah, 1995). Standard KT/V (stdKT/V), introduced by Gotch, is another variant of FSR (Gotch, 1998). The time-average solute concentration $\left(C_{t a}\right)$ has been introduced to define 'equivalent renal clearance' (EKR), as a solute removal rate over $C_{\text {ta }}$ (Casino \& Lopez, 1996). Using other reference concentrations in the definition of EKR instead of $\mathrm{C}_{\mathrm{ta}}$, the general idea of equivalent continuous clearance, ECC, can be formulated (Waniewski et al., 2006; Waniewski et al., 2010). There are at least four different reference methods: 1) peak, p, 2) peak average, pa, 3) time average, ta, and 4) treatment time average, trta, reference values of volume, mass, and concentration applied in KT/V, FSR and ECC (Waniewski et al., 2006; Waniewski et al., 2010). KT/V, FSR and ECC are mathematically related for the same reference method. However, the choice of an adequacy index and the respective reference method is not obvious. It is not possible to decide whether this or the other definition is better although some authors have declared their preferences (Keshaviah, 1995; Casino \& Lopez, 1996; Verrina et al., 1998; Henderson, 1999). The difference between different hypotheses and the indices based on them may be investigated theoretically, but the choice, if any, may be done only on the basis of a large set of clinical data. Future research should hopefully provide more information about the relationship between various definitions and the probability of clinical outcome in dialyzed patients.

Recent studies report some advantages of low-efficiency, frequent schedule over short, highefficiency HD (Depner, 1998; Charra et al., 2004). The two compartment variable volume urea kinetic model can be applied to examine the whole set of dialysis adequacy indices in different dialysis treatments, e.g. 1) conventional HD with 3 sessions per week, 2) daily HD with 6 sessions per week and 3) nocturnal HD with 6 long sessions using typical patient and treatment parameters. The peak average reference method used in FSR and ECC calculations seem to be a more sensitive to the frequency and time of dialysis than the method based on time average reference (Waniewski et al., 2006; Waniewski et al., 2010).

The unified approach to the definition of dialysis adequacy indices proposed by Waniewski et al. is valid for all modalities of dialysis performed in end-stage renal disease and acute renal failure patients and for the assessment of residual renal function (Waniewski et al., 2006; Debowska et al., 2010; Waniewski et al., 2010). The integrated system of dialysis adequacy indices takes into account all currently applied indices and allows to explain their relationships and specificities.

The theory and practical application of this system of adequacy indices are here presented on the basis of our previous publications and a (unpublished) $\mathrm{PhD}$ thesis (Waniewski \& Lindholm, 2004; Debowska \& Waniewski, 2005; Debowska et al., 2005; Waniewski et al., 2006; Debowska et al., 2007a; Debowska et al., 2007b; Debowska et al., 2010; Waniewski et al., 2010). 


\section{Theory of fluid and solute transport in hemodialysis}

The mathematical description of hemodialysis includes two parts: 1) one part that explains the fluid and solute transport across a semi-permeable membrane of the dialyzer, and 2) one part that characterizes the global solute transport between removal device and patient.

\subsection{Solute and fluid transport in dialyzer}

The fluid and solute transport in dialyzer consists of two processes: transport through a permselective membrane between blood and dialysate and transport in blood and dialysate channels.

The theoretical description of transport through a permselective membrane is based on phenomenological (thermodynamic) descriptions according to the Staverman-KedemKatchalsky-Spiegler approach (Staverman, 1951; Kedem \& Katchalsky, 1958; Katchalsky \& Curran, 1965; Spiegler \& Kedem, 1966; Weryński \& Nowosielcew, 1983; Werynski \& Waniewski, 1995; Waniewski, 2006). Diffusion is the dominant factor for small solute transport in hemodialyzer. The transport due to convection prevails in hemofilters, plasma separators, etc. In hemodialyzer with highly permeable membrane used in hemodiafiltration, the convective transport component plays a leading role in the removal of middle molecules and small proteins (Werynski \& Waniewski, 1995).

Considering the dialyzer as shown in Fig. 1, the system will soon after the start of dialysis be at the quasi-steady state with the mass balance:

$$
\mathrm{Q}_{\mathrm{b}, \mathrm{i}} \mathrm{C}_{\mathrm{b}, \mathrm{i}}+\mathrm{Q}_{\mathrm{d}, \mathrm{i}} \mathrm{C}_{\mathrm{d}, \mathrm{i}}=\left(\mathrm{Q}_{\mathrm{b}, \mathrm{i}}-\mathrm{Q}_{\mathrm{v}}\right) \mathrm{C}_{\mathrm{b}, \mathrm{o}}+\left(\mathrm{Q}_{\mathrm{d}, \mathrm{i}}+\mathrm{Q}_{\mathrm{v}}\right) \mathrm{C}_{\mathrm{d}, \mathrm{o}}
$$

where $Q_{b, o}=Q_{b, i}-Q_{v}$ and $Q_{d, o}=Q_{d, i}+Q_{v}$ are the rates of blood and dialysate flows at the outlet of hemodialyzer, respectively, $\mathrm{Q}_{\mathrm{v}}$ is ultrafiltration rate, $\mathrm{C}_{\mathrm{b}, \mathrm{i}}$ and $\mathrm{C}_{\mathrm{d}, \mathrm{i}}$ are the inlet blood and dialysate concentrations and $C_{b, o}$ and $C_{d, o}$ are the outlet blood and dialysate concentrations, respectively.

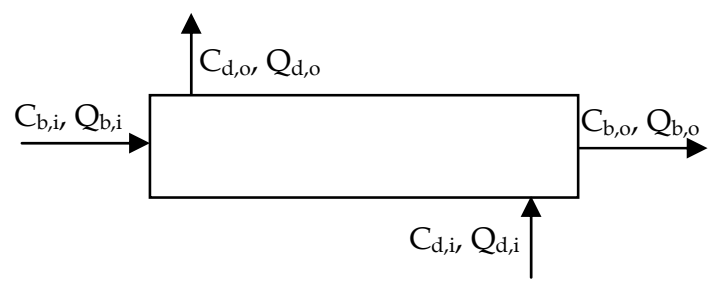

Fig. 1. Schematic description of concentration and flows in dialyzer.

After rearrangement of equation (1):

$$
Q_{b, i}\left(C_{b, i}-C_{b, o}\right)+Q_{v} C_{b, o}=Q_{d, i}\left(C_{d, o}-C_{d, i}\right)+Q_{v} C_{d, o}
$$

The left side of equation (2) represents the solute leaving the blood; the right side is the solute appearing in dialysate. The first term on each side of equation (2) is the diffusive component of flux and the second term represents the convective contribution.

At any specific blood and dialysis fluid flow rates, the diffusive dialysance $\mathrm{D}$ is the change in solute amount of incoming blood over concentration driving force $\left(C_{b, i}-C_{d, i}\right)$ : 


$$
\mathrm{D}=\frac{\mathrm{Q}_{\mathrm{b}, \mathrm{i}}\left(\mathrm{C}_{\mathrm{b}, \mathrm{i}}-\mathrm{C}_{\mathrm{b}, \mathrm{o}}\right)}{\mathrm{C}_{\mathrm{b}, \mathrm{i}}-\mathrm{C}_{\mathrm{d}, \mathrm{i}}}=\frac{\mathrm{Q}_{\mathrm{d}, \mathrm{i}}\left(\mathrm{C}_{\mathrm{d}, \mathrm{o}}-\mathrm{C}_{\mathrm{d}, \mathrm{i}}\right)}{\mathrm{C}_{\mathrm{b}, \mathrm{i}}-\mathrm{C}_{\mathrm{d}, \mathrm{i}}}
$$

Assuming that solute concentration in the inflowing dialysate is zero $\left(C_{d, i}=0\right)$ equation (3) yields the definition of diffusive clearance $\mathrm{K}$ :

$$
K=\frac{Q_{b, i}\left(C_{b, i}-C_{b, o}\right)}{C_{b, i}}
$$

Dialyzer clearance is a parameter that describes the efficiency of membrane devices, i.e. the solute removal rate from the blood related to blood solute concentration at the inlet to the hemodialyzer (Darowski et al., 2000; Waniewski, 2006).

Ultrafiltration $Q_{v}$ from blood to dialysate increases diffusive solute transport from blood to dialysate and therefore the clearance of the hemodialyzer or hemofilter may be described as:

$$
\mathrm{K}=\mathrm{K}_{0}+\mathrm{T}_{\mathrm{r}} \cdot \mathrm{Q}_{\mathrm{v}}
$$

where $K_{0}$ is the diffusive clearance for $Q_{v}=0$ and $T_{r}$ is the transmittance coefficient (Werynski \& Waniewski, 1995; Darowski et al., 2000; Waniewski, 2006). Although the dependence of $K$ on $Q_{v}$ in the one-dimensional theory is slightly nonlinear, one may assume the linear description used in equation (5) that was confirmed experimentally with high accuracy (Waniewski et al., 1991). $\mathrm{T}_{\mathrm{r}}$ may be estimated from the experimental data using the equation:

$$
\mathrm{T}_{\mathrm{r}}=\frac{\mathrm{K}-\mathrm{K}_{0}}{\mathrm{Q}_{\mathrm{v}}}
$$

The measurements of $K_{0}$ and $K$ for a few different values of $Q_{v}$ allow determining $T_{r}$ using equation (6) and linear regression.

\subsection{One and two compartment models for the distribution of fluid and solutes in the body}

Compartment models consider the patient body as a single compartment (thick line in Fig. 2) or as two compartments: intracellular and extracellular (dashed line in Fig. 2).

The one compartment model of the solute distribution volume assumes that solute mass, $\mathrm{M}_{\mathrm{b}}$, is distributed in the body in a single, homogenous pool of volume $\mathrm{V}_{\mathrm{b}}$ with concentration $\mathrm{C}_{\mathrm{b}}$. The two compartment model assumes that body fluid is divided into two parts: one directly (extracellular compartment, described by solute mass $\mathrm{M}_{\mathrm{e}}$, concentration $\mathrm{C}_{\mathrm{e}}$ and fluid volume $\mathrm{V}_{\mathrm{e}}$ ) and one indirectly (intracellular compartment, with solute mass $\mathrm{M}_{\mathrm{i}}$, concentration $C_{i}$ and fluid volume $V_{i}$ ) accessible for dialysis (Schneditz \& Daugirdas, 2001). It is assumed that solute generation, at the rate $G$, and water intake, at the rate $G_{w}$, occur only in the extracellular space. In the two compartment model, solute and water removal by the kidneys, with clearances $\mathrm{K}_{\mathrm{r}}$ and $\mathrm{K}_{\mathrm{rw}}$, respectively, are also related only to the extracellular compartment.

Some authors use more general terminology for the two compartment model with perfused and non-perfused compartments, without deciding a priori about their physiological interpretation. This terminology may be used for the description of the distribution of small 


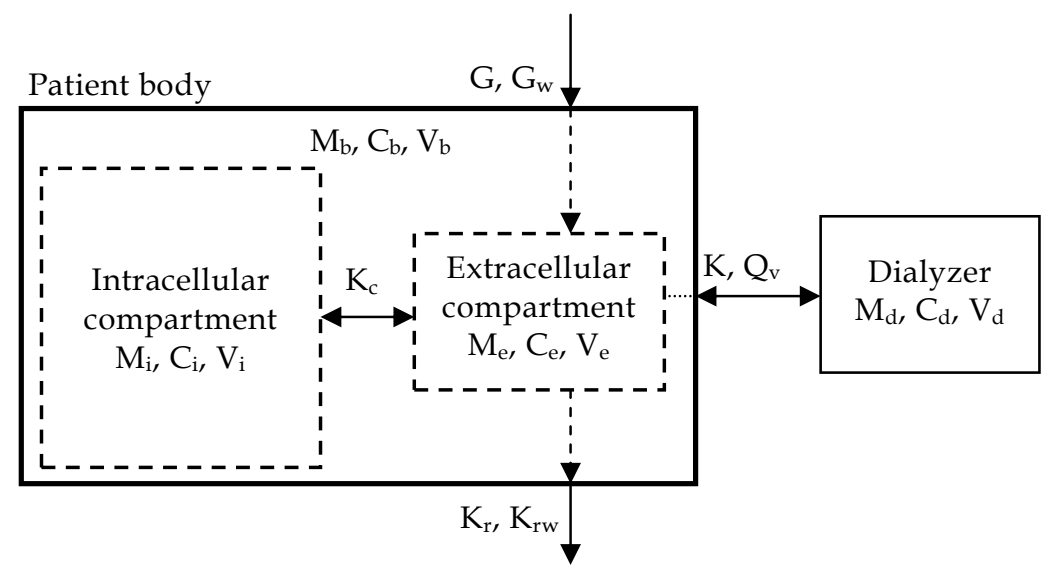

Fig. 2. One and two compartment models for the distribution of water and solutes in the body.

solutes (as urea and creatinine) and proteins (as $\beta_{2}$-microglobulin). In some papers, extracellular and intracellular water were called perfused and non-perfused compartments, respectively (Clark et al., 1999; Leypoldt et al., 2003; Leypoldt et al., 2004).

In one compartment model the rate of the change of solute mass in the body, $\mathrm{dM}_{\mathrm{b}} / \mathrm{dt}=\mathrm{d}\left(\mathrm{C}_{\mathrm{b}} \mathrm{V}_{\mathrm{b}}\right) / \mathrm{dt}$, and in dialysate, $\mathrm{dM}_{\mathrm{d}} / \mathrm{dt}=\mathrm{d}\left(\mathrm{C}_{\mathrm{d}} \mathrm{V}_{\mathrm{d}}\right) / \mathrm{dt}$, during hemodialysis, are described by the following ordinary differential equations:

$$
\left\{\begin{array}{l}
\frac{d\left(C_{b} V_{b}\right)}{d t}=G-K\left(C_{b}-C_{d}\right)-K_{r} C_{b} \\
\frac{d\left(C_{d} V_{d}\right)}{d t}=K\left(C_{b}-C_{d}\right)
\end{array}\right.
$$

In the two compartment model, the removal of solute by the dialyzer with clearance $\mathrm{K}$ and by the kidneys with residual clearance $K_{r}$, is a function of the solute concentration in the extracellular compartment, $\mathrm{C}_{\mathrm{e}}$, but indirectly depends also on the intercompartmental mass transport coefficient $\mathrm{K}_{\mathrm{c}}$ :

$$
\left\{\begin{array}{l}
\frac{d\left(V_{e} C_{e}\right)}{d t}=K_{c}\left(C_{i}-C_{e}\right)-K\left(C_{e}-C_{d}\right)+G-K_{r} C_{e} \\
\frac{d\left(V_{i} C_{i}\right)}{d t}=-K_{c}\left(C_{i}-C_{e}\right) \\
\frac{d\left(V_{d} C_{d}\right)}{d t}=K\left(C_{e}-C_{d}\right)
\end{array}\right.
$$

For urea and creatinine, $C_{d}=0$ in standard hemodialysis and hemofiltration treatments, because fresh dialysis fluid without these solutes is continuously provided. The rate of total solute mass removal from the body, $\mathrm{dM}_{\mathrm{R}} / \mathrm{dt}$, during hemodialysis is:

$$
\frac{\mathrm{dM}_{\mathrm{R}}}{\mathrm{dt}}=\mathrm{K}\left(\mathrm{C}_{\mathrm{e}}-\mathrm{C}_{\mathrm{d}}\right)+\mathrm{K}_{\mathrm{r}} \mathrm{C}_{\mathrm{e}}
$$


The total solute amount removed from the body $\Delta \mathrm{M}_{\mathrm{R}}$ is the mass removed by dialyzer with clearance $\mathrm{K}$ and by the kidneys with residual clearance $\mathrm{K}_{\mathrm{r}}$. The solute removal by dialyzer is proportional to the solute concentration gradient between dialysate and extracellular compartment $\left(\mathrm{C}_{\mathrm{e}}-\mathrm{C}_{\mathrm{d}}\right)$ when using the two compartment model. In the one compartment model, the body solute concentration $C_{b}$ is used in equation (9) instead of $C_{e}$.

In the two compartment model, the changes of fluid volume in extracellular and intracellular compartments, $\mathrm{V}_{\mathrm{e}}(\mathrm{t})$ and $\mathrm{V}_{\mathrm{i}}(\mathrm{t})$, respectively, are assumed to be proportional to the volumes of these compartments (Canaud et al., 1995; Clark et al., 1998; Ziolko et al., 2000):

$$
\mathrm{V}_{\mathrm{e}}(\mathrm{t})=\mathrm{a} \cdot \mathrm{V}_{\mathrm{b}}(\mathrm{t}), \mathrm{V}_{\mathrm{i}}(\mathrm{t})=(1-\mathrm{a}) \cdot \mathrm{V}_{\mathrm{b}}(\mathrm{t})
$$

where $\alpha$ is usually about $1 / 3, V_{b}$ for urea and creatinine is assumed to be equal to total body water (TBW) and $V_{b}$ as well as $V_{e}$ can be measured by bioimpedance (Zaluska et al., 2002). During HD the change of solute distribution volume is described by a linear relationship:

$$
\mathrm{V}_{\mathrm{b}}(\mathrm{t})=\mathrm{V}_{\mathrm{b}}\left(\mathrm{t}_{0}\right)+\beta \cdot \mathrm{t}
$$

where $\mathrm{V}_{\mathrm{b}}\left(\mathrm{t}_{0}\right)$ is the initial volume of solute distribution and the rate of volume change:

$$
\beta=\mathrm{G}_{\mathrm{w}}-\mathrm{K}_{\mathrm{rw}}-\mathrm{Q}_{\mathrm{v}}
$$

consists of water intake with rate $\mathrm{G}_{\mathrm{w}}$, residual water clearance $\mathrm{K}_{\mathrm{rw}}$ and ultrafiltration with rate $Q_{v}$.

\section{Hemodialysis efficiency: history and definitions of dialysis adequacy indices}

The questions concerning how to quantify dialysis dose and how much dialysis should be provided, are controversial and have been debated since the beginning of the dialysis treatment era. Between 1976 and 1981, the National Cooperative Dialysis Study (NCDS) was performed in the United States to establish objective, quantitative criteria for the adequate dose of dialysis (Gotch \& Sargent, 1985; Sargent \& Gotch, 1989; Locatelli et al., 2005). It included 165 patients and had a $2 \times 2$ factorial design: the patients were randomized to two different midweek pre-dialysis blood urea nitrogen (BUN) levels (70 vs. $120 \mathrm{mg} / \mathrm{dL}$ ) and two different treatment times (2.5 - 3.5 vs. $4.5-5.0 \mathrm{~h})$.

Concentration targeting in this study used a time average BUN concentration $\left(\mathrm{C}_{\mathrm{ta}}\right)$ of $50 \mathrm{mg} / \mathrm{dL}$ (groups I and III) and $100 \mathrm{mg} / \mathrm{dL}$ (groups II and IV). Dialysis time was fixed for the protocol; hence, dialyzer clearance was the main treatment parameter that was adjusted. A one compartment variable volume model was used to prescribe and control the treatment. Urea kinetic modeling was applied to determine protein catabolic rate (pcr) and the parameters of dialysis necessary to achieve a specified BUN level with thrice weekly treatments. BUN changes in an individual patient were quantified as the product of dialyzer urea clearance $(\mathrm{K}$, $\mathrm{mL} / \mathrm{min}$ ) and the treatment time $(\mathrm{T}, \mathrm{min})$, normalized to the urea distribution volume $(\mathrm{V}, \mathrm{mL})$. $\mathrm{KT} / \mathrm{V}$ exponentially determines the total decrease in BUN during a dialysis treatment:

$$
\mathrm{C}_{\text {post }}=\mathrm{C}_{\text {pre }} \mathrm{e}^{-\frac{\mathrm{KT}}{\mathrm{V}}}
$$


$\mathrm{C}_{\text {post }}$ and $\mathrm{C}_{\text {pre }}$ are postdialysis and predialysis blood urea concentration. KT/V was prescribed in the NCDS as a function of pcr and $C_{\text {pre: }}$ :

$$
-\frac{\mathrm{KT}}{\mathrm{V}}=\ln \left(1-\frac{0.49 \mathrm{pcr}-0.16)}{\mathrm{C}_{\text {pre }}}\right)
$$

The primary analysis showed that morbidity was less at lower levels of urea $C_{t a}$ and the number of deaths in patients assigned to groups II and IV was very high (Parker et al., 1983). No significant effect of treatment time was found, although there was a clear trend towards a benefit from longer dialysis $(\mathrm{p}=0.06)$.

The 'mechanistic' analysis of the NCDS data done by Gotch and Sargent launched the issue of urea KT/V (Gotch \& Sargent, 1985). The patient groups II and IV, with high BUN, had low KT/V values at all levels of pcr and the groups I and III, with low pcr, had low levels of $\mathrm{BUN}$ and $\mathrm{KT} / \mathrm{V}$. For Kt/V $>0.8$ the data base was comprised almost entirely of patient groups I and III with pcr $>0.8$. KT/V $<0.8$ provided inadequate dialysis with high probability of failure irrespective of pcr.

The factor KT/V was described as the "fractional clearance of urea" (Gotch \& Sargent, 1985). If $\mathrm{K}$ is the urea clearance and $\mathrm{T}$ is time, the term $\mathrm{KT}$ is a volume. The ratio of $\mathrm{KT}$ to $\mathrm{V}$ expresses the fraction of the urea distribution volume that is totally cleared from urea.

\subsection{Fast hemodialysis: two compartment effects, single-pool and equilibrated KT/V}

The human body has a large number of physical compartments. The mathematical description of body is usually simplified by considering it as single pool (one compartment) or as a few interconnected pools. In a multicompartment model, the solute and fluid transport between body spaces should be described.

The one compartment model assumes that the body acts as a single, well mixed space and is characterized by: 1) high permeability of cells to the solute being modeled, 2) rapidly flowing blood that transports the solute throughout a totally perfused body. The assumptions of one compartment model for urea or creatinine during dialysis are valid as long as the flux of solute into and out of cells is faster than the flux of solute from the extracellular space accessible to dialysis. When the intercompartment flow between body compartments is too slow and constrained in comparison with the solute removal rate from the perfused compartment, then the solute behavior increasingly deviates from that of one compartment kinetics.

With the available high efficiency dialyzers and the tendency to short-time, rapid dialysis at least the two compartment modeling appears to be necessary. The two compartment model assumes solute generation to and removal from the perfused space, which is for urea and creatinine typically the extracellular compartment. This assumption is considered reasonable because urea is produced in the liver and enters body water from the systemic circulation (Sargent \& Gotch, 1989). Regarding creatinine, in most studies the previously determined urea distribution volumes for each patient were successfully used as an approximation for creatinine distribution space (Canaud et al., 1995; Clark et al., 1998; Waikar \& Bonventre, 2009).

The perfused (extracellular) compartment communicates with the non-perfused compartment (intracellular) according to the concentration gradient with an intercompartmental mass transport coefficient $\left(\mathrm{K}_{\mathrm{c}}, \mathrm{mL} / \mathrm{min}\right)$. For a low value of $\mathrm{K}_{\mathrm{c}}$, the 
discrepancy between one and two compartment modeling is larger because the immediate intercompartmental flow is precluded (Debowska et al., 2007b).

Assuming one compartment model, a fixed distribution volume (no ultrafiltration) and no generation during the dialysis, as during a short HD session, the concentration of any solute can be described by the equation (Sargent \& Gotch, 1989; Daugirdas et al., 2001):

$$
\mathrm{C}_{\mathrm{t}}=\mathrm{C}_{\text {pre }} \cdot \mathrm{e}^{-\mathrm{K} \cdot \mathrm{t} / \mathrm{V}}
$$

where $C_{t}$ is the blood concentration of the solute at any time $t$ during dialysis, $C_{\text {pre }}$ is the blood concentration at the beginning of $\mathrm{HD}, \mathrm{K}$ is the clearance of applied dialyzer, and $\mathrm{V}$ is the solute distribution volume.

The single pool KT/V (spKT/V) for urea is determined from equation (15) as the natural logarithm $(\mathrm{ln})$ of the ratio of postdialysis $\left(\mathrm{C}_{\text {post }}\right)$ to predialysis $\left(\mathrm{C}_{\text {pre }}\right)$ plasma urea concentrations (Gotch \& Sargent, 1985; Daugirdas et al., 2001):

$$
\operatorname{spKT} / \mathrm{V}=-\ln \left(\frac{\mathrm{C}_{\text {post }}}{\mathrm{C}_{\text {pre }}}\right)
$$

The expression $1-C_{\text {post }} / C_{\text {pre, }}$ is called urea reduction ratio (URR):

$$
\mathrm{URR}=1-\mathrm{R}
$$

where

$$
\mathrm{R}=\frac{\mathrm{C}_{\text {post }}}{\mathrm{C}_{\text {pre }}}
$$

A solute like urea or creatinine is however removed during hemodialysis more efficiently from the extracellular than from the intracellular compartment and its concentration in plasma falls faster than expected when assessed by one compartment modeling; this effect is called urea inbound (Daugirdas et al., 2001), Fig. 3. When dialysis is completed, the flow from intracellular to extracellular compartment causes a fast increase of postdialysis urea concentration in plasma, i.e., urea rebound (Daugirdas et al., 2001; Daugirdas et al., 2004), Fig. 3. Even if solute removal from a compartment directly accessible to dialyzer is relatively efficient during an intermittent therapy, the overall solute removal may be limited by slow intercompartmental mass transfer. Urea concentration measured in plasma represents the extracellular urea concentration.

The effects of urea generation and urea removal due to solute convective transport that are not included in the basic relation between spKT/V and URR can be corrected by Daugirdas formula (Daugirdas, 1993):

$$
\mathrm{spKT} / \mathrm{V}=-\ln (\mathrm{R}-0.008 \cdot \mathrm{T})+(4-3.5 \cdot \mathrm{R}) \cdot \mathrm{UF} / \mathrm{W}
$$

where $\mathrm{T}$ is treatment time in hour, UF is ultrafiltration volume and $\mathrm{W}$ is the postdialysis weight (in kilograms). Single-pool kinetics overestimates however the removed amount of urea because of the postdialysis urea rebound, which is an compartmental effect, and therefore the equilibrated $\mathrm{KT} / \mathrm{V}$ (eqKT/V) was introduced to clinical practice to be estimated by the following formula (Daugirdas et al., 2001):

$$
\text { eqKT } / V=-\ln \left(R_{e q}-0.008 \cdot T\right)+\left(4-3.5 \cdot R_{e q}\right) \cdot U F / W
$$




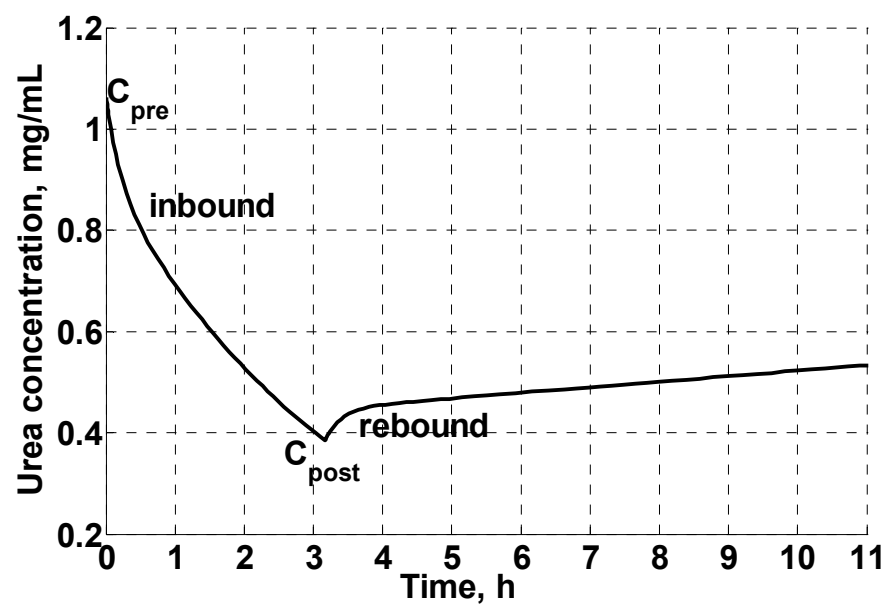

Fig. 3. The phenomena of the intradialytic drop in urea concentration in plasma (inbound), and the postdialysis increase in urea concentration in plasma (rebound).

where

$$
\mathrm{R}_{\mathrm{eq}}=\frac{\mathrm{C}\left(\mathrm{T}_{\mathrm{eq}}\right)}{\mathrm{C}_{0}}
$$

$\mathrm{C}\left(\mathrm{T}_{\text {eq }}\right)$ is the urea concentration 30 to 60 minutes after the dialysis session. The eqKT/V is typically about $0.2 \mathrm{KT} / \mathrm{V}$ unit lower than the spKt/V, but this difference depends on the efficiency, or rate of dialysis (Daugirdas et al., 2001). Equilibrated KT/V values can be also calculated using an alternative equation, as described by Daugirdas and Schneditz (Daugirdas \& Schneditz, 1995):

$$
\mathrm{eqKT} / \mathrm{V}=\mathrm{spKT} / \mathrm{V}-0.6 \cdot \frac{\mathrm{spKT} / \mathrm{V}}{\mathrm{T}}+0.03
$$

or the formula derived from observations during the HEMO Study (Depner et al., 1999; Eknoyan et al., 2002; Daugirdas et al., 2004):

$$
\text { eqKT } / \mathrm{V}=\operatorname{spKT} / \mathrm{V}-0.39 \cdot \frac{\mathrm{spKT} / \mathrm{V}}{\mathrm{T}}
$$

or that introduced by Tattersall et al. (Tattersall et al., 1996):

$$
\text { eqKT } / V=\operatorname{spKT} / V \cdot \frac{T}{T+36}
$$

where $\mathrm{T}$ indicates treatment time in minutes. Equations (22) and (23), were derived from regression using the rebounded BUN measured 30 or 60 minutes after dialysis. The Tattersall equation was derived from theoretical considerations of disequilibrium and rebound, but the coefficient was derived from fitting to clinical data. 


\subsection{Urea KT/V and creatinine clearance for the kidneys}

To assess the residual renal function (RRF) urine is usually collected for 24 hours and analyzed for urea as well as creatinine (Daugirdas et al., 2001). Residual renal clearance for a particular substance can be calculated as follows:

$$
\mathrm{K}_{\mathrm{r}}=\frac{\text { excretion rate }}{\mathrm{C}_{\mathrm{e}}}=\frac{\mathrm{C}_{\text {urine }} \mathrm{V}_{\text {urine }}}{\mathrm{T}_{\text {urine }}} \frac{1}{\mathrm{C}_{\mathrm{e}}}=\frac{\Delta \mathrm{M}_{\mathrm{r}}}{\mathrm{T}_{\text {urine }}} \frac{1}{\mathrm{C}_{\mathrm{e}}}
$$

where $V_{\text {urine }}$ is urine volume, $C_{\text {urine }}$ is solute concentration in urine, $T_{\text {urine }}$ is time of urine collection, $C_{e}$ is plasma solute concentration and $\Delta \mathrm{M}_{\mathrm{r}}$ is solute mass removed by the kidneys. Weekly KT/V for the kidney for 1 week time is expressed as follows:

$$
\text { weekly }(\mathrm{KT} / \mathrm{V})_{\mathrm{RRF}}=\frac{7 \cdot \mathrm{C}_{\text {urine }} \mathrm{V}_{\text {urine }}}{\mathrm{C}_{\mathrm{e}} \mathrm{V}_{\mathrm{b}}}=\frac{7 \cdot \Delta \mathrm{M}_{\mathrm{r}}}{\mathrm{M}_{\mathrm{b}}}
$$

where $\mathrm{M}_{\mathrm{b}}$ is solute mass in the body, $\mathrm{V}_{\mathrm{b}}$ is TBW and other symbols have the same meaning as in equation (25).

In clinical practice, the most popular methods used for evaluation RRF is creatinine clearance $\left(\mathrm{Cl}_{\mathrm{Cr}}\right)$, calculated as follows:

$$
\text { weekly } \mathrm{Cl}_{\mathrm{Cr}, \mathrm{RRF}}=\frac{7 \cdot \Delta \mathrm{M}_{\mathrm{R}, \mathrm{Cr}}}{1 \text { week } \cdot \mathrm{C}_{\mathrm{e}, \mathrm{Cr}}} \frac{1.73}{\text { BSA }}
$$

where $\Delta \mathrm{M}_{\mathrm{R}, \mathrm{Cr}}$ is creatinine total mass removed during one day due to therapy and by residual renal function, $\mathrm{C}_{\mathrm{e}, \mathrm{Cr}}$ is serum creatinine concentration, $\mathrm{BSA}$ is body surface area and 1.73 is the average BSA for a typical human. Weekly creatinine clearance is the most often expressed in L for 1 week.

\subsection{Equivalent renal clearance (EKR)}

In a steady state, during continuous dialytic treatment or/and with renal function, the solute generation rate $\mathrm{G}$ is balanced by the solute removal rate $\mathrm{K}_{\mathrm{ss}}$ determining in this way the constant concentration $\mathrm{C}_{\mathrm{ss}}$ within the patient body (Gotch, 2001):

$$
\mathrm{C}_{\mathrm{ss}}=\mathrm{G} / \mathrm{K}_{\mathrm{ss}}
$$

The $\mathrm{K}_{\mathrm{ss}}$ is defined by rearrangement of equation (28):

$$
\mathrm{K}_{\mathrm{ss}}=\mathrm{G} / \mathrm{C}_{\mathrm{ss}}
$$

Calculation of a continuous clearance $\mathrm{K}_{\mathrm{ss}}$, equivalent to the amount of dialysis provided by any intermittent dialysis schedule, $K_{\text {eq, }}$ requires calculation of $G$ and the concentration profile, and selection of a point on this profile, which may be considered to be equivalent to, e.g. weekly, the oscillating concentration $\left(\mathrm{C}_{\mathrm{eq}}\right)$ according to: $\mathrm{K}_{\mathrm{eq}}=\mathrm{G} / \mathrm{C}_{\mathrm{eq}}$. This approach to the clearance calculation has been reported using different definitions of $C_{\text {eq. }}$. The peak concentration hypothesis defined $\mathrm{C}_{\mathrm{eq}}$ as the maximum solute concentration, within e.g. one week duration. The mean predialysis (peak average) solute concentration was used to define standard K (stdK) (Gotch, 1998). The time-average solute concentration $\left(\mathrm{C}_{\mathrm{ta}}\right)$ has been introduced to define 'equivalent renal clearance' (EKR) (Casino \& Lopez, 1996): 


$$
\mathrm{EKR}=\frac{\mathrm{G}}{\mathrm{C}_{\mathrm{ta}}}
$$

The equation (30) may be used in metabolically stable patients, whereas in acute renal failure patients the definition for EKR requires a more unifying form (Casino \& Marshall, 2004):

$$
\mathrm{EKR}=\frac{\Delta \mathrm{M}_{\mathrm{R}} / \mathrm{T}}{\mathrm{C}_{\mathrm{ta}}}
$$

where $\Delta \mathrm{M}_{\mathrm{R}}$ is total solute amount removed by replacement therapy and the kidneys, and $\mathrm{T}$ is arbitrary assumed time. EKR, in the form of equation (31), is determined as solute removal rate over time average solute concentration.

\subsection{Standardized KT/V}

Taking into account the average predialysis urea concentration, Gotch introduced the standard KT/V (stdKT/V) concept to measure the relative efficiency of the whole spectrum of dialytic therapies whether intermittent, continuous or mixed (Gotch, 1998). The stdKT/V was defined with a relation between urea generation, expressed by its equivalent normalized protein catabolic rate $(\mathrm{nPCR})$ and the peak average urea concentration $\left(\mathrm{C}_{\mathrm{pa}}\right)$ of all the weekly values (Gotch, 1998; Diaz-Buxo \& Loredo, 2006):

$$
\operatorname{stdKT} / \mathrm{V}=\frac{0.184(\mathrm{nPCR}-0.17) \cdot \mathrm{V} \cdot 0.001}{\mathrm{C}_{\mathrm{pa}}} \cdot \frac{7 \cdot 1440}{\mathrm{~V}}
$$

where $0.184(\mathrm{nPCR}-0.17) \mathrm{V} \cdot 0.001$ is equal to urea generation rate $\mathrm{G}(\mathrm{mg} / \mathrm{min}), \mathrm{V}$ is body water in $\mathrm{mL}$ and 7.1440 is number of minutes in one week's time. Predialysis urea concentration $\left(C_{p a}\right)$ - for any combination of frequency of intermittent HD (IHD), automated peritoneal dialysis (APD) and continuous dialysis between IHD or APD sessions - was defined as follows (Gotch, 1998):

$$
C_{\mathrm{pa}}=\frac{\frac{\mathrm{G}}{(\mathrm{spKT} / \mathrm{V}) \cdot \mathrm{V} / \mathrm{T}}\left(1-\mathrm{e}^{-\mathrm{eqKT} / \mathrm{V}}\right) \mathrm{e}^{-\frac{\left(\mathrm{K}_{\mathrm{p}}+\mathrm{K}_{\mathrm{r}}\right)((\mathrm{T} / \mathrm{N}) 1440-\mathrm{T})}{\mathrm{V}}}+\frac{\mathrm{G}}{\mathrm{K}_{\mathrm{p}}+\mathrm{K}_{\mathrm{r}}}\left(1-\mathrm{e}^{-\frac{\left(\mathrm{K}_{\mathrm{p}}+\mathrm{K}_{\mathrm{r}}\right)((\mathrm{T} / \mathrm{N}) 1440-\mathrm{T})}{\mathrm{V}}}\right)}{\left(1-\mathrm{e}^{-\mathrm{eqKT} / \mathrm{V}}\right) \mathrm{e}^{-\frac{\left(\mathrm{K}_{\mathrm{p}}+\mathrm{K}_{\mathrm{f}}\right)((\mathrm{T} / \mathrm{N}) 1440-\mathrm{T})}{\mathrm{V}}}}
$$

where $K, K_{p}$ and $K_{r}$ are dialyzer, peritoneal and renal urea clearances, respectively, $T$ is duration of treatment sessions, $\mathrm{N}$ is the frequency of IHD or APD per week and eqKT/V is the equilibrated $\mathrm{KT} / \mathrm{V}$ calculated according to equation (22).

Assuming a symmetric weekly schedule of dialysis sessions, no residual renal function, and a fixed solute distribution volume $\mathrm{V}$, Leypoldt et al. obtained an analytical relationship between stdKT/V, spKT/V and eqKT/V (Leypoldt et al., 2004):

$$
\operatorname{stdKT} / \mathrm{V}=\frac{10080 \frac{1-\mathrm{e}^{-\mathrm{eqKT} / \mathrm{V}}}{\mathrm{T}}}{\frac{1-\mathrm{e}^{-\mathrm{eqKT} / \mathrm{V}}}{\mathrm{spKT} / \mathrm{V}}+\frac{10080}{\mathrm{~N} \cdot \mathrm{T}}-1}
$$


where $\mathrm{N}$ is number of treatments per week and eqKT/V is derived from spKT/V by using one of the equations (20), (22), (23) or (24). stdKT/V calculated using equation (34) differs slightly from stdKT/V using the exact method, equation (32), that takes into account among other things asymmetry of weekly schedule and $K_{\mathrm{r}}$ (Leypoldt et al., 2004). The stdKT/V is a method to measure the efficiency of HD of variable frequency, continuous peritoneal dialysis (PD), intermittent PD, continuous renal replacement therapies and residual renal function (Diaz-Buxo \& Loredo, 2006).

\subsection{Solute removal index (SRI) and fractional solute removal (FSR)}

An alternative for KT/V is fractional solute removal (FSR), which was suggested by Verrina et al. (Verrina et al., 1998) and Henderson (Henderson, 1999) for comparative studies of different dialysis modalities and schedules. The concept of FSR is closely related to the concept of the solute removal index (SRI) proposed by Keshaviah (Keshaviah, 1995).

SRI was defined for HD as the ratio of net solute removed during a dialysis session (i.e., the solute amount removed minus the solute amount generated in the same time period) over the initial solute amount in the body. This parameter is however useless for comparative analysis of different dialysis modalities and schedules. Its numerical value for the kidneys and continuous therapies, such as continuous ambulatory peritoneal dialysis (CAPD), is by definition equal to zero (Waniewski \& Lindholm, 2004). Therefore, Keshaviah (Keshaviah, 1995) used for CAPD and automated peritoneal dialysis the definition of SRI as the ratio of solute removed during a dialysis session over its initial amount in the body, i.e., the definition of FSR.

\subsection{International guidelines on HD dose}

According to the Kidney Disease Outcomes Quality Initiative (KDOQI) guidelines the minimally adequate dose of thrice-weekly $\mathrm{HD}$ in patients with residual renal clearance $\left(\mathrm{K}_{\mathrm{r}}\right)$ less than $2 \mathrm{~mL} / \mathrm{min} / 1.73 \mathrm{~m}^{2}$ should be urea single pool $\mathrm{KT} / \mathrm{V}$ (excluding residual renal function) of 1.2 per dialysis (i.e., an average urea reduction ratio of 65\%), (Work Group, 2001). KDOQI Work Group emphasizes that the literature clearly supports the delivery of a minimum hemodialysis dose of at least urea $\mathrm{spKt} / \mathrm{V}=1.2$, but does not suggest an optimal dose. Identification of an optimal dose of hemodialysis would require evaluation of patient status and clinical outcomes including survival analyses and assessment of quality of life as well as the cost-effectiveness of different hemodialysis regimens. Until such data are available, the Work Group states that the hemodialysis dose recommended is to be regarded as a minimum value only (Work Group, 2001; Work Group, 2006).

The European Best Practice Guidelines recommend higher values: the minimum prescribed $\mathrm{HD}$ dose per session for thrice-weekly schedule as equilibrated $\mathrm{KT} / \mathrm{V}$ for urea is set at 1.2; this corresponds to a value of spKT/V equal to 1.4 (Work Group, 2002).

\section{Integrated system of dialysis adequacy indices}

The integrated system of dialysis adequacy indices aims to include currently applied indices, systemize their definitions and explain relationships between them. The unified approach to the dialysis adequacy proposed by Waniewski et al. is valid for all modalities of dialysis performed in end-stage renal disease and acute renal failure patients, and for the assessment of residual renal function (Waniewski et al., 2006; Debowska et al., 2010; Waniewski et al., 2010). 


\subsection{Different definition variants of $\mathrm{KT} / \mathrm{V}$, equivalent continuous clearance (ECC) and fractional solute removal (FSR)}

For the assessment of dialysis efficacy, a few different adequacy indices can be used: a) KT/V (K - dialyzer clearance, $\mathrm{T}$ - treatment time, V - solute distribution volume), b) equivalent continuous clearance, ECC and c) fractional solute removal, FSR.

There are at least four different reference methods: 1) peak, $p, 2)$ peak average, pa, 3) time average, $t a$, and 4) treatment time average, trta, reference values of concentration, mass and volume, applied in ECC, FSR and KT/V definitions, respectively (ref $=p$, ref $=$ pa, ref $=$ ta and ref $=$ trta), (Waniewski et al., 2006). For certain applications also minimal average or minimal reference methods are used, e.g. in equation (19) post-dialysis minimal weight is included in calculation of $s p K T / V$. The peak value is the maximal value of solute concentration or mass, the peak average value is calculated as the average of pretreatment values (before each HD session), the time average value is the average calculated over the whole cycle of dialysis, $\mathrm{T}_{\mathrm{c}}$, and the treatment time average value is calculated as the average for the time $\mathrm{T}$ when dialysis was performed, Fig. 4.
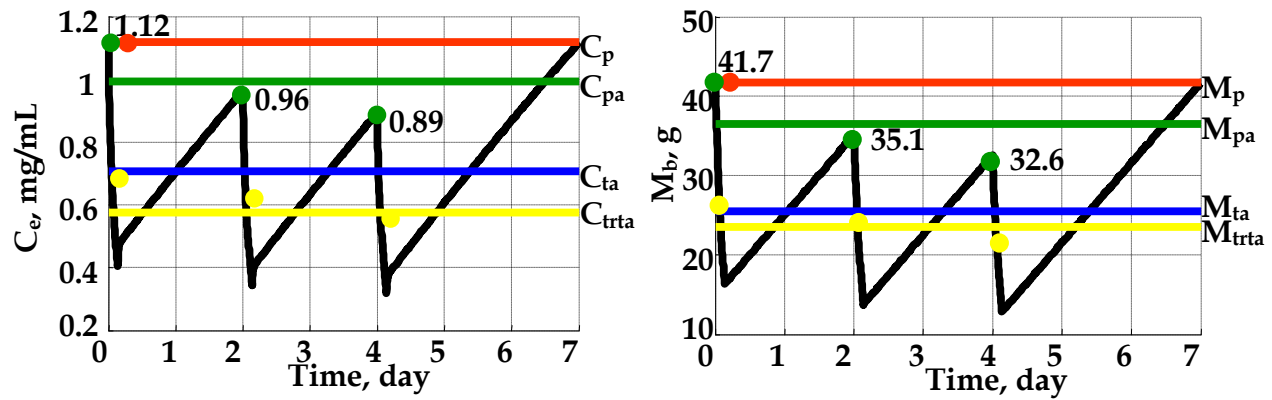

Fig. 4. Examples showing urea concentration in extracellular compartment (left side) and urea mass in patient body (right side) during a cycle of three hemodialysis sessions.

The reference solute distribution volume is calculated as the reference mass over the reference concentration:

$$
\mathrm{V}_{\text {ref }}=\mathrm{M}_{\mathrm{b}, \text { ref }} / \mathrm{C}_{\text {ref }}
$$

Note, that $V_{\text {ref }}$ defined in this way may be different from the volume calculated in analogy to

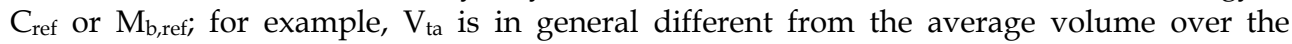
treatment time.

For $\mathrm{HD}$, dialyzer clearance $\mathrm{K}$ is equal to the average effective dialyzer clearance $\mathrm{K}_{\mathrm{T}}$ defined as solute mass removed from the body during dialysis $M_{R d}$, per the treatment time, $T$, and per the average solute concentration in extracellular compartment during treatment time, $\mathrm{C}_{\text {trta }}\left(\mathrm{K}=\mathrm{K}_{\mathrm{T}}=\Delta \mathrm{M}_{\mathrm{Rd}} / \mathrm{T} / \mathrm{C}_{\text {trta }}\right)$, (Waniewski \& Lindholm, 2004; Waniewski et al., 2006).

Another concept of clearance, equivalent renal clearance, EKR $(\mathrm{mL} / \mathrm{min})$, was proposed by Casino \& Lopez for metabolically stable patients, equation (30), but for metabolically unstable patients equation (31) should be used (Casino \& Lopez, 1996; Casino \& Marshall, 2004), c.f. section 3.3. Using a different concentration in EKR instead of $C_{t a}$, a general definition of equivalent continuous clearance, ECC, may be formulated (Waniewski et al., 2006; Waniewski et al., 2010), Table 1: 


$$
\mathrm{ECC}_{\mathrm{ref}}=\frac{\Delta \mathrm{M}_{\mathrm{R}}}{\mathrm{t} \cdot \mathrm{C}_{\mathrm{ref}}}
$$

where index "ref" denotes a reference concentration, e.g. ref $=$ ta or ref $=p$, etc. If the patient is in a steady metabolic state, i.e. after a cycle time $\left(\mathrm{T}_{\mathrm{c}}\right)$ the solute concentration and solute mass in the body return to their initial values, then the total amount of solute removed during $T_{c}$ is equal to the solute amount generated during $T_{c}$. Thus, for the metabolic steady state and $t=T_{c}$ :

$$
\Delta \mathrm{M}_{\mathrm{R}}=\mathrm{G} \cdot \mathrm{T}_{\mathrm{c}}
$$

If one scales the total removed solute mass to some reference mass $\left(\mathrm{M}_{\mathrm{b}, \mathrm{ref}}\right)$ then a nondimensional parameter - fractional solute removal, FSR - may be defined as follows (Gotch, 1998; Waniewski \& Lindholm, 2004; Waniewski et al., 2006), Table 1:

$$
\mathrm{FSR}_{\mathrm{ref}}=\frac{\Delta \mathrm{M}_{\mathrm{R}}}{\mathrm{M}_{\mathrm{b}, \mathrm{ref}}}
$$

FSR is often called the solute removal index (SRI), although originally SRI was defined as the solute amount removed minus the solute amount generated in the same time over the initial solute amount in the body, Table 1, (Keshaviah, 1995; Waniewski \& Lindholm, 2004, Waniewski et al., 2010).

\begin{tabular}{l|l|l}
\hline $\begin{array}{l}\text { Reference } \\
\text { method }\end{array}$ & $\begin{array}{l}\text { Equivalent Continuous Clearance } \\
\text { ECC }\end{array}$ & $\begin{array}{l}\text { Fractional Solute Removal } \\
\text { FSR }\end{array}$ \\
\hline $\begin{array}{l}\text { peak, } \\
\mathrm{p}\end{array}$ & $\mathrm{ECC}_{\mathrm{p}}=\frac{\Delta \mathrm{M}_{\mathrm{R}} / \mathrm{T}_{\mathrm{c}}}{\mathrm{C}_{\mathrm{p}}}$ & $\mathrm{FSR}_{\mathrm{p}}=\frac{\Delta \mathrm{M}_{\mathrm{R}}}{\mathrm{M}_{\mathrm{b}, \mathrm{p}}}$ \\
$($ Henderson, 1999), SRI, (Keshaviah, 1995)
\end{tabular}

Table 1. Summary of dialysis adequacy indices.

In particular, EKR is equal to a particular version of ECC (ECC $\left.\mathrm{E}_{\mathrm{ta}}\right)$, equation (36), that was used in many clinical and theoretical studies, Table 1 (Casino \& Lopez, 1996; Verrina et al., 1998; Clark et al., 1999; Leypoldt et al., 2003; Casino \& Marshall, 2004; Waniewski et al., 2006). If ref = pa (where pa denotes the average predialysis concentration) then $\mathrm{ECC}_{\mathrm{pa}}$ is equal to stdK defined by Gotch and used in some clinical and theoretical studies, Table 1 (Gotch, 1998; Gotch 
et al., 2000; Leypoldt et al., 2003; Leypoldt et al., 2004; Waniewski et al., 2006). Both these clearances were defined initially for the metabolic steady state using formula (30), (Casino \& Lopez, 1996; Gotch, 1998; Gotch et al., 2000), and were later generalized to the general case using formula (36), (Casino \& Marshall, 2004; Debowska et al., 2010).

ECC and FSR are not independent indices but they are correlated (Debowska et al., 2005; Waniewski et al., 2006):

$$
\mathrm{ECC}_{\text {ref }}=\frac{\mathrm{V}_{\text {ref }}}{\mathrm{t}} \mathrm{FSR}_{\text {ref }}
$$

where $\mathrm{ECC}_{\text {ref }}$ and $\mathrm{FSR}_{\text {ref }}$ may be calculated for the same time interval $\mathrm{t}$; a practically important case is $t=T_{c}$. The coefficient of proportionality, $V_{\text {ref }} / t$, depends on the choice of reference method, because $\mathrm{V}_{\text {ref }}$ is defined as $\mathrm{V}_{\text {ref }}=\mathrm{M}_{\mathrm{b} \text {,ref }} / \mathrm{C}_{\text {ref, }}$ equation (35). Furthermore, if $t=T_{c}$ and the residual renal clearance is $K_{r}$, then FSR is related to KT/V (Waniewski et al., 2006):

$$
\mathrm{FSR}_{\text {ref }}=\frac{\mathrm{C}_{\text {trta }}}{\mathrm{C}_{\text {ref }}} \frac{\mathrm{KT}}{\mathrm{V}_{\text {ref }}}+\frac{\mathrm{C}_{\text {ta }}}{\mathrm{C}_{\text {ref }}} \frac{\mathrm{K}_{\mathrm{r}} \mathrm{T}_{\mathrm{c}}}{\mathrm{V}_{\text {ref }}}
$$

because

$$
\Delta \mathrm{M}_{\mathrm{R}}=\Delta \mathrm{M}_{\mathrm{Rd}}+\Delta \mathrm{M}_{\mathrm{r}}, \Delta \mathrm{M}_{\mathrm{Rd}}=\mathrm{K} \cdot \mathrm{T} \cdot \mathrm{C}_{\mathrm{trta}}, \Delta \mathrm{M}_{\mathrm{r}}=\mathrm{K}_{\mathrm{r}} \cdot \mathrm{T}_{\mathrm{c}} \cdot \mathrm{C}_{\mathrm{ta}}
$$

where $\Delta M_{R d}$ and $\Delta M_{r}$ are the removed solute mass by replacement therapy and the kidneys, respectively. Another correlation can be found between $\mathrm{ECC}$ and $\mathrm{K}$ for $\mathrm{t}=\mathrm{T}_{\mathrm{c}}$ (Waniewski et al., 2006):

$$
\mathrm{ECC}_{\text {ref }}=\frac{\mathrm{C}_{\text {trta }}}{\mathrm{C}_{\text {ref }}} \frac{\mathrm{T}}{\mathrm{T}_{\mathrm{c}}} \mathrm{K}+\frac{\mathrm{C}_{\text {ta }}}{\mathrm{C}_{\text {ref }}} \mathrm{K}_{\mathrm{r}}
$$

The relationships between ECC and FSR, FSR and KT/V and between ECC and K, equations (39), (40) and (42), respectively, follow directly from their definitions and are valid for all reference methods and any patient and treatment modality (Waniewski et al., 2006). They do not depend on the assumption of the metabolic steady state. However, the coefficients in these relationships, which involve the ratios of different reference concentrations, must be calculated for each patient and treatment schedule separately.

\subsection{Typical modalities and schedules for hemodialysis}

Different dialysis modalities and schedules are applied in clinics to treat patients with endstage renal diseases. Although solute removal indices are normalized by the solute amount in the body (with the body size included), many other parameters and conditions may differ as the patients are treated by different forms of dialysis (continuous or automated PD, HD, or combination of PD and HD), different number of sessions per week, different duration of each session, and therefore the values of dialysis adequacy indices depend on the details of dialysis. Numerical simulations of different HD regimes were performed using solute kinetic modeling and the obtained solute mass, concentration and distribution volume profiles in body compartments and solute concentration, mass and volume of dialysate were used to calculate dialysis adequacy indices. The two compartment variable volume model, 
equation (8), was implemented in the computer program Matlab and solved by numerical integration (Runge-Kutta method) to describe the solute and fluid transport between patient and removal device during dialysis.

\subsection{Comparison of adequacy indices for different HD regimes based on computer simulations}

The objective of the analysis presented here was to compare different adequacy parameters and their different definitions for different schedules of HD, Table 2:

1. Conventional, daily hemodialysis with three 219-minute sessions (HD3x)

2. Daily hemodialysis with six 147-minute sessions (HD6xd)

3. Nocturnal hemodialysis with six 401-minute sessions (HD6xn)

Values of HD duration and dialyzer clearance were taken to be the average for patients groups enrolled in the Frequent Hemodialysis Network Daily and Nocturnal clinical trails (Daugirdas et al., 2010). Computer simulations were carried out for several weeks of the treatment to achieve the metabolic steady state of the patient.

\begin{tabular}{l|cc}
\hline Label & Time schedule & $\mathrm{K}, \mathrm{mL} / \mathrm{min}$ \\
\hline HD3x & $3 \times 219 \mathrm{~min}$ & 272 \\
HD6xd & $6 \times 147 \mathrm{~min}$ & 277 \\
HD6xn & $6 \times 401 \mathrm{~min}$ & 170 \\
\hline
\end{tabular}

Table 2. Time schedule and dialyzer clearance $\mathrm{K}$ for: conventional hemodialysis provided three times a week (HD3x), daily hemodialysis carried out six times a week (HD6xd) and long, nocturnal hemodialysis (HD6xn).

Other parameters were: urea generation rate, $G=7 \mathrm{mg} / \mathrm{min}$, residual urea clearance $\mathrm{K}_{\mathrm{r}}=0.6 \mathrm{~mL} / \mathrm{min}$. The convective transport of the solute was characterized by transmittance coefficient, $\mathrm{T}_{\mathrm{r}}=0.3$, equation (5), for hemodialyzer. For the two compartment model, it was assumed that the intercompartmental clearance $\mathrm{K}_{\mathrm{c}}=600 \mathrm{~mL} / \mathrm{min}$ and volumes of extracellular and intracellular compartments were changed according to equation (10) with $\alpha=1 / 3$. The postdialysis water distribution volume was $V_{b}=40 \mathrm{~L}$; water was generated with constant rate $\left(\mathrm{G}_{\mathrm{w}}=1.04 \mathrm{~mL} / \mathrm{min}\right)$; weekly $10.5 \mathrm{~L}$ of water was removed by means of residual water clearance $\left(\mathrm{K}_{\mathrm{rw}}=0.1 \mathrm{~mL} / \mathrm{min}\right)$ and as a result of ultrafiltration $\mathrm{Q}_{\mathrm{v}}$.

The changes of urea concentration in the extracellular compartment of the body and the values of FSR, as obtained by computer simulations using parameters from Table 2, were shown in Fig. 5 and Fig. 6. The time average concentration, $C_{t a}$, was $0.5 \mathrm{mg} / \mathrm{mL}$ in conventional HD performed three times per week and $0.36 \mathrm{mg} / \mathrm{mL}$ and $0.22 \mathrm{mg} / \mathrm{mL}$ for daily and nocturnal HD carried out six times per week, respectively, Fig. 5 and Table 3. The amplitude of urea concentration changes had the highest values for HD3x and the lowest for HD6xn, Fig. 5 and Table 3.

The weekly values of ECC and FSR, according to all methods for the definition of reference values, equations (36) and (38), and the respective values of urea concentrations in blood, $\mathrm{C}_{\text {ref, }}$ are shown in Table 3. The adequacy indices were different, with the indices ECC and FSR for HD3x being lower than for HD6xd and HD6xn, Table 3.

The adequacy indices, ECC and FSR, had the highest values for the definitions based on treatment time (trta) reference method and the lowest values for the definitions based on the peak reference method (Table 3), and were between weekly $\mathrm{ECC}_{\mathrm{ta}}=14.03 \mathrm{~mL} / \mathrm{min}$ and 

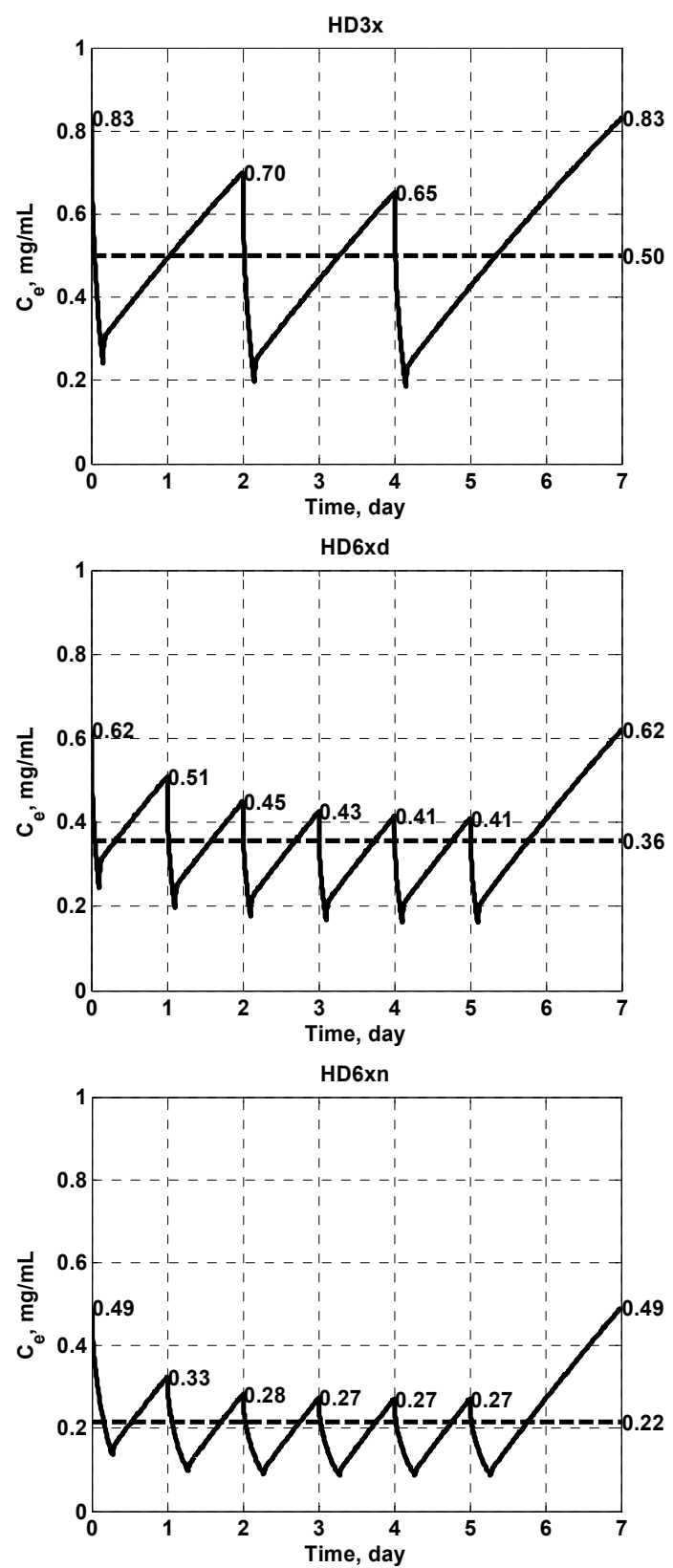

Fig. 5. Urea concentration, $\mathrm{C}_{\mathrm{e}}$, in the extracellular compartment during conventional hemodialysis provided three times a week (HD3x), daily hemodialysis carried out six times a week (HD6xd) and long, nocturnal hemodialysis (HD6xn). Average urea concentration was plotted with dashed line. 

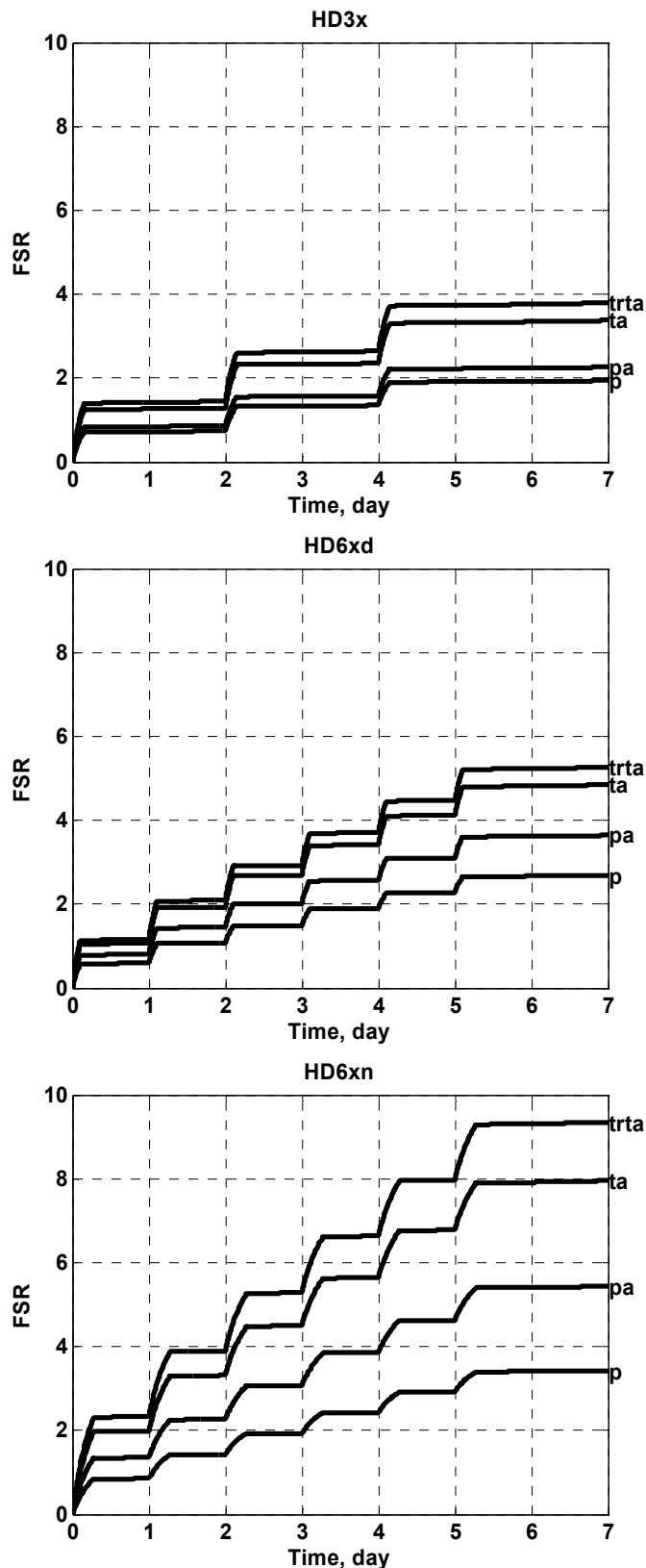

Fig. 6. FSR, normalized by peak, p, peak average, pa, time average, ta, and treatment time average, trta, urea mass in the body during conventional hemodialysis provided three times a week (HD3x), daily hemodialysis carried out six times a week (HD6xd) and long, nocturnal hemodialysis (HD6xn). 
$\mathrm{FSR}_{\mathrm{pa}}=2.26$ for HD3x and weekly $\mathrm{ECC}_{\mathrm{ta}}=32.3 \mathrm{~mL} / \mathrm{min}$ and $\mathrm{FSR}_{\mathrm{pa}}=5.44$ for HD6xn, indicating more efficient solute removal with HD6xn. The difference between the values of the indices calculated according to different definitions (treatment time average, time average, peak average, peak) was high (up to 192\%).

The ratio of ECC and FSR differed slightly between the modalities and definitions (range, $4.04-4.96 \mathrm{~mL} / \mathrm{min}$ ) and correlated with the fluctuations of water volume and urea concentration in the body, as shown by $V_{\text {ref, }}$ Table 3 . Nevertheless, equation (39) is valid for all investigated applications. Because the cycle time was the same for all simulated dialysis modalities, $T_{c}=1$ week, thus the correlation between the ratio of ECC to FSR and water volume confirmed the relationship described by equation (39).

\begin{tabular}{c|lccccc}
\hline & & ECC & FSR & $\frac{\text { ECC }}{\text { FSR }}$ & $V_{\text {ref }}$ & $C_{\text {ref }}$ \\
\hline HD3x & $\mathrm{p}$ & 8.42 & 1.94 & 4.34 & 43.76 & 0.83 \\
& pa & 9.62 & 2.26 & 4.25 & 42.85 & 0.73 \\
& ta & 14.03 & 3.38 & 4.16 & 41.90 & 0.50 \\
& trta & 18.83 & 3.80 & 4.96 & 50.01 & 0.37 \\
\hline HD6xd & p & $11.28(34 \%)$ & $2.69(39 \%)$ & 4.20 & 42.32 & 0.62 \\
& pa & $14.84(54 \%)$ & $3.64(61 \%)$ & 4.08 & 41.11 & 0.47 \\
& ta & $19.71(40 \%)$ & $4.85(43 \%)$ & 4.07 & 40.99 & 0.36 \\
& trta & $25.31(34 \%)$ & $5.26(38 \%)$ & 4.81 & 48.46 & 0.28 \\
\hline HD6xn & p & $14.25(69 \%)$ & $3.42(76 \%)$ & 4.17 & 41.99 & 0.49 \\
& pa & $21.94(128 \%)$ & $5.44(141 \%)$ & 4.04 & 40.69 & 0.32 \\
& ta & $32.3(130 \%)$ & $7.95(135 \%)$ & 4.06 & 40.93 & 0.22 \\
& trta & $41.66(121 \%)$ & $9.35(146 \%)$ & 4.45 & 44.90 & 0.17 \\
\hline
\end{tabular}

Table 3. Weekly ECC, FSR, the ratio of ECC to FSR, the solute distribution volume, $\mathrm{V}_{\text {ref, }}$ and urea concentration in extracellular compartment, $\mathrm{C}_{\text {ref, }}$, calculated according to four different definitions: peak (p), peak average (pa), time average (ta) and treatment time average (trta) for conventional hemodialysis provided three times a week (HD3x), daily hemodialysis carried out six times a week (HD6xd) and long, nocturnal hemodialysis (HD6xn). Values in brackets present the difference in relation to conventional HD (in percent).

The formula for the relationship between FSR and KT/V, equation (40), shows that FSR may be represented as a weighted sum of $K T / V$ and $\mathrm{K}_{\mathrm{r}} \mathrm{T}_{\mathrm{c}} / \mathrm{V}$, with the first term representing the urea removal by dialysis and the second one, the urea removal by residual clearance. The weighing coefficients are the ratios of the average urea concentration in blood during dialysis treatment over the reference urea concentration and the average urea concentration in blood during the whole treatment cycle over the reference concentration, respectively, Table 4. These coefficients depend on the reference method as well as the treatment modality and schedule.

ECC may be related to $K$ and $K_{r}$ using equation (42). For that purpose $K$ must be recalculated by the factor $T / T_{c}$, and then the recalculated value of $K$ and the value of $K_{r}$ are summed up with the same weighing coefficients that appear in formula (40) for the relationship of FSR and KT/V. The weighing coefficients show how much the average concentrations, during effective treatment time $\mathrm{T}$, and during the whole cycle time $\mathrm{T}_{\mathrm{c}}$, respectively, differ from the reference concentration, Table 4. 


\begin{tabular}{|c|c|c|c|c|c|c|}
\hline & & $\frac{\mathrm{KT}}{\mathrm{V}_{\text {ref }}}$ & $\frac{\mathrm{K}_{\mathrm{r}} \mathrm{T}_{\mathrm{c}}}{\mathrm{V}_{\mathrm{ref}}}$ & $\frac{C_{\text {trta }}}{C_{\text {ref }}}$ & $\frac{C_{\text {ta }}}{C_{\text {ref }}}$ & FSR \\
\hline \multirow[t]{4}{*}{ HD3x } & $p$ & 4.15 & 0.14 & 0.45 & 0.60 & 1.94 \\
\hline & pa & 4.24 & 0.14 & 0.51 & 0.69 & 2.26 \\
\hline & ta & 4.34 & 0.14 & 0.75 & 1.00 & 3.38 \\
\hline & trta & 3.63 & 0.12 & 1.00 & 1.34 & 3.80 \\
\hline \multirow[t]{4}{*}{ HD6xd } & $p$ & 5.85 & 0.14 & 0.45 & 0.57 & 2.69 \\
\hline & pa & 6.02 & 0.15 & 0.59 & 0.75 & 3.64 \\
\hline & ta & 6.04 & 0.15 & 0.78 & 1.00 & 4.85 \\
\hline & trta & 5.10 & 0.12 & 1.00 & 1.28 & 5.26 \\
\hline \multirow[t]{4}{*}{ HD6xn } & $p$ & 9.82 & 0.14 & 0.34 & 0.44 & 3.42 \\
\hline & pa & 10.13 & 0.15 & 0.53 & 0.68 & 5.44 \\
\hline & ta & 10.07 & 0.15 & 0.78 & 1.00 & 7.95 \\
\hline & trta & 9.18 & 0.13 & 1.00 & 1.29 & 9.35 \\
\hline
\end{tabular}

Table 4. Nondimensional parameters $\mathrm{KT} / \mathrm{V}_{\text {ref, }}$ residual $\mathrm{K}_{\mathrm{r}} \mathrm{T}_{\mathrm{c}} / \mathrm{V}_{\text {ref, }}$ the ratio of treatment time average to reference urea concentration $C_{\text {trta }} / C_{\text {ref, }}$, the ratio of time average to reference urea concentration $\mathrm{C}_{\mathrm{ta}} / \mathrm{C}_{\text {ref }}$ and fractional solute removal, FSR, equation (40), for conventional hemodialysis provided three times a week (HD3x), daily hemodialysis carried out six times a week (HD6xd) and long, nocturnal hemodialysis (HD6xn).

ECC and FSR were found to be equivalent descriptions of dialysis, if the same reference method (peak, peak average, time average, treatment time average) was used, as suggested by equation (39). The ratio of ECC and FSR was similar for all definitions, in contrast to much different values of the indices themselves.

\section{Adequacy indices for steady and non-steady metabolic state}

The change of solute mass in the body during dialysis is due to the generation minus removal, but, in general, one can not assume that the solute removal is equal to the generation during the cycle time (i.e. intra- plus inter-dialysis time), especially in acute renal failure, ARF, patients; thus, even the measurement of removed solute in spent dialysate or filtrate does not necessarily accurately reflect the generated mass. In such cases, the real solute generation rate needs to be estimated using computer simulations for specific patients and dialysis parameters by fitting the theoretical predictions to the solute concentration profile using equation (8) for simulation. The calculation of FSR and ECC should then be based on equations (38) and (36) as it was shown by Debowska et al. (Debowska et al., 2010).

\section{Conclusions}

A unified scheme was proposed for the definitions of the adequacy indices on the basis of the reference values for: 1) normalization of removed solute mass to body solute mass (FSR), 2) cleared water volume to urea distribution volume (KT/V), and 3) solute generation rate to solute concentration in blood (ECC). The selection of the reference method can be done using respectively: peak ( $\mathrm{p}$ ), peak average (pa), time average (over the whole treatment cycle, ta) and treatment time average (over time of all dialysis sessions during the treatment cycle, trta) values of solute mass or concentration. It is not clear a priori which reference 
method should be used (ref $=p$, ref $=p a, r e f=$ ta or ref $=$ trta) for the assessment of the treatment adequacy. To get a consistent scheme of definitions and relationships, the reference solute distribution volume was defined as $\mathrm{V}_{\text {ref }}=\mathrm{M}_{\mathrm{b} \text {,ref }} / \mathrm{C}_{\text {ref. }}$. For each reference method, three adequacy indices, FSR, KT/V and ECC, can be defined. The computer simulations demonstrated that these indices are related, and that the relationships follow their definitions.

In general, ECC is equivalent to FSR, equation (39), if the same type of reference method is applied for both parameters (Debowska et al., 2005; Waniewski et al., 2006). The coefficient of proportionality, $\mathrm{V}_{\mathrm{ref}} / \mathrm{T}_{\mathrm{c}}$, depends only slightly on the details of the procedure, especially on the schedule of water removal and the degree of total body water variation during the treatment cycle as well as the difference between urea concentrations in intracellular and extracellular compartments that may develop during dialysis sessions. Nevertheless, the variations of $V_{\text {ref }}$ between different definitions and procedures for the same patient are small. If a reference method ( $\mathrm{p}, \mathrm{pa}, \mathrm{ta}, \mathrm{trta})$ of FSR and ECC definitions is fixed, then the changes in FSR are reflected by the changes in ECC and vice versa for the same patient. However, this relationship is different for patients with different total body water, which may also differ between patient populations.

One advantage of using equivalent continuous clearance, ECC, or fractional solute removal, FSR, is that these indices permit comparison of hemodialysis and peritoneal dialysis doses, and allow the addition of the contributions from HD, PD and residual renal function into the whole index for solute removal efficiency, and thus these indices could provide a basis for setting one standard target dose for all patients regardless of dialysis modality, frequency and duration (Depner, 2005; Debowska et al., 2007a). Note that ECC and FSR may also be successfully applied in continuous and semi-continuous therapies (e.g. continuous veno-venous hemofiltration, $\mathrm{CVVH}$, slow low-efficiency daily dialysis, SLEDD) in patients with acute renal failure (Clark et al., 1999; Leypoldt et al., 2003; Debowska et al., 2010).

From the beginning of the era of dialysis treatment, there has been a quest for the optimal dialysis index. The history reflects the complexity of this matter, and attempts to simplify the meander way of this process that has not yet been finished because different versions of existing dialysis modalities are applied, new therapies are being introduced into clinical practices as new techniques become available. Compartmental models and solute kinetic analysis, presented here, used for the mathematical and computer-based description of delivered dose of dialysis are important tools for the evaluation of dialysis adequacy.

\section{References}

Canaud, B., Garred, L. J., Argiles, A., Flavier, J. L., Bouloux, C. \& Mion, C. (1995). Creatinine kinetic modelling: a simple and reliable tool for the assessment of protein nutritional status in haemodialysis patients. Nephrol Dial Transplant, Vol. 10, No. 8, pp. (1405-10)

Casino, F. G. \& Lopez, T. (1996). The equivalent renal urea clearance: a new parameter to assess dialysis dose. Nephrol Dial Transplant, Vol. 11, No. 8, pp. (1574-81)

Casino, F. G. \& Marshall, M. R. (2004). Simple and accurate quantification of dialysis in acute renal failure patients during either urea non-steady state or treatment with irregular or continuous schedules. Nephrol Dial Transplant, Vol. 19, No. 6, pp. (145466) 
Charra, B., Terrat, J. C., Vanel, T., Chazot, C., Jean, G., Hurot, J. M. \& Lorriaux, C. (2004). Long thrice weekly hemodialysis: the Tassin experience. Int J Artif Organs, Vol. 27, No. 4, pp. (265-83)

Clark, W. R., Leypoldt, J. K., Henderson, L. W., Mueller, B. A., Scott, M. K. \& Vonesh, E. F. (1999). Quantifying the effect of changes in the hemodialysis prescription on effective solute removal with a mathematical model. J Am Soc Nephrol, Vol. 10, No. 3, pp. (601-9)

Clark, W. R., Mueller, B. A., Kraus, M. A. \& Macias, W. L. (1998). Quantification of creatinine kinetic parameters in patients with acute renal failure. Kidney Int, Vol. 54, No. 2, pp. (554-60)

Darowski, M., Orłowski, T., Weryński, A. \& Wójcicki, J. M. (2000). Biocybernetyka i Inżynieria Biomedyczna Akademicka Oficyna Wydawnicza Exit, 83-87674-25-7, Warszawa

Daugirdas, J. T. (1993). Second generation logarithmic estimates of single-pool variable volume Kt/V: an analysis of error. J Am Soc Nephrol, Vol. 4, No. 5, pp. (1205-13)

Daugirdas, J. T., Blake, G. \& Ing, T. S. (2001). Handbook of Dialysis (3rd ed.), Lippincott Williams \& Wilkins, 0-316-17381-9, Philadelphia

Daugirdas, J. T., Depner, T. A., Greene, T., Levin, N. W., Chertow, G. M. \& Rocco, M. V. (2010). Standard Kt/Vurea: a method of calculation that includes effects of fluid removal and residual kidney clearance. Kidney Int, Vol. 77, No. 7, pp. (637-44)

Daugirdas, J. T., Greene, T., Depner, T. A., Leypoldt, J., Gotch, F., Schulman, G. \& Star, R. (2004). Factors that affect postdialysis rebound in serum urea concentration, including the rate of dialysis: results from the HEMO Study. J Am Soc Nephrol, Vol. 15, No. 1, pp. (194-203)

Daugirdas, J. T. \& Schneditz, D. (1995). Overestimation of hemodialysis dose depends on dialysis efficiency by regional blood flow but not by conventional two pool urea kinetic analysis. Asaio J, Vol. 41, No. 3, pp. (M719-24)

Debowska, M. \& Waniewski, J. (2005). Comparison of dialysis adequacy indices calculated according to one and two compartment model. Bio-Algorithms And Med-Systems, Vol. 1, No. 1, pp. (205-208)

Debowska, M., Waniewski, J. \& Lindholm, B. (2005). Dialysis adequacy indices for peritoneal dialysis and hemodialysis. Adv Perit Dial, Vol. 21, pp. (94-7)

Debowska, M., Waniewski, J. \& Lindholm, B. (2007a). Bimodal dialysis: theoretical and computational investigations of adequacy indices for combined use of peritoneal dialysis and hemodialysis. Asaio J, Vol. 53, No. 5, pp. (566-75)

Debowska, M., Waniewski, J. \& Lindholm, B. (2007b). An integrative description of dialysis adequacy indices for different treatment modalities and schedules of dialysis. Artif Organs, Vol. 31, No. 1, pp. (61-9)

Debowska, M., Waniewski, J. \& Lindholm, B. (2010). Adequacy indices for dialysis in acute renal failure: kinetic modeling. Artif Organs, Vol. 34, No. 5, pp. (412-419)

Depner, T., Beck, G., Daugirdas, J., Kusek, J. \& Eknoyan, G. (1999). Lessons from the Hemodialysis (HEMO) Study: an improved measure of the actual hemodialysis dose. Am J Kidney Dis, Vol. 33, No. 1, pp. (142-9)

Depner, T. A. (1998). Benefits of more frequent dialysis: lower TAC at the same Kt/V. Nephrol Dial Transplant, Vol. 13 Suppl 6, pp. (20-4)

Depner, T. A. (2005). Hemodialysis adequacy: basic essentials and practical points for the nephrologist in training. Hemodial Int, Vol. 9, No. 3, pp. (241-54) 
Diaz-Buxo, J. A. \& Loredo, J. P. (2006). Standard Kt/V: comparison of calculation methods. Artif Organs, Vol. 30, No. 3, pp. (178-85)

Eknoyan, G., Beck, G. J., Cheung, A. K., Daugirdas, J. T., Greene, T., Kusek, J. W., Allon, M., Bailey, J., Delmez, J. A., Depner, T. A., Dwyer, J. T., Levey, A. S., Levin, N. W., Milford, E., Ornt, D. B., Rocco, M. V., Schulman, G., Schwab, S. J., Teehan, B. P. \& Toto, R. (2002). Effect of dialysis dose and membrane flux in maintenance hemodialysis. N Engl J Med, Vol. 347, No. 25, pp. (2010-9)

Gotch, F. A. (1998). The current place of urea kinetic modelling with respect to different dialysis modalities. Nephrol Dial Transplant, Vol. 13 Suppl 6, pp. (10-4)

Gotch, F. A. (2001). Is Kt/V Urea a Satisfactory Measure for Dosing the Newer Dialysis Regimens? Semin Dial, Vol. 14, No. 1, pp. (15-17)

Gotch, F. A. \& Sargent, J. A. (1985). A mechanistic analysis of the National Cooperative Dialysis Study (NCDS). Kidney Int, Vol. 28, No. 3, pp. (526-34)

Gotch, F. A., Sargent, J. A. \& Keen, M. L. (2000). Whither goest Kt/V? Kidney Int Suppl, Vol. 76, pp. (3-18)

Henderson, L. W. (1999). Critical interpretation of adequacy parameters in peritoneal dialysis and hemodialysis. Perit Dial Int, Vol. 19 Suppl 2, pp. (S38-44)

Katchalsky, A. \& Curran, P. (1965). Nonequilibrium thermodynamics in biophysics Harvard University Press, Cambridge

Kedem, O. \& Katchalsky, A. (1958). Thermodynamic analysis of the permeability of biological membranes to non-electrolytes. Biochim Biophysic Acta, Vol. 27, pp. (229246)

Keshaviah, P. (1995). The solute removal index--a unified basis for comparing disparate therapies. Perit Dial Int, Vol. 15, No. 2, pp. (101-4)

Leypoldt, J. K., Jaber, B. L., Lysaght, M. J., McCarthy, J. T. \& Moran, J. (2003). Kinetics and dosing predictions for daily haemofiltration. Nephrol Dial Transplant, Vol. 18, No. 4, pp. (769-76)

Leypoldt, J. K., Jaber, B. L. \& Zimmerman, D. L. (2004). Predicting treatment dose for novel therapies using urea standard Kt/V. Semin Dial, Vol. 17, No. 2, pp. (142-5)

Locatelli, F., Buoncristiani, U., Canaud, B., Kohler, H., Petitclerc, T. \& Zucchelli, P. (2005). Dialysis dose and frequency. Nephrol Dial Transplant, Vol. 20, No. 2, pp. (285-96)

Lowrie, E. G., Chertow, G. M., Lew, N. L., Lazarus, J. M. \& Owen, W. F. (1999). The urea [clearance $\mathrm{x}$ dialysis time] product $(\mathrm{Kt})$ as an outcome-based measure of hemodialysis dose. Kidney Int, Vol. 56, No. 2, pp. (729-37)

Parker, T. F., Laird, N. M. \& Lowrie, E. G. (1983). Comparison of the study groups in the National Cooperative Dialysis Study and a description of morbidity, mortality, and patient withdrawal. Kidney Int Suppl, No. 13, pp. (S42-9)

Sargent, J. A. \& Gotch, F. A. (1989). Replacement of renal function by dialysis Kluwer Academic Publishers,

Schneditz, D. \& Daugirdas, J. T. (2001). Compartment effects in hemodialysis. Semin Dial, Vol. 14, No. 4, pp. (271-7)

Spiegler, K. \& Kedem, O. (1966). Thermodynamics of hyperfiltration (reverse osmosis): criteria for efficient membranes. Desalination, Vol. 1, pp. (311-326)

Staverman, A. (1951). The theory of measurement of osmotic pressure. Rac trav chim, Vol. 70, pp. (344-352) 
Tattersall, J. E., DeTakats, D., Chamney, P., Greenwood, R. N. \& Farrington, K. (1996). The post-hemodialysis rebound: predicting and quantifying its effect on Kt/V. Kidney Int, Vol. 50, No. 6, pp. (2094-102)

Verrina, E., Brendolan, A., Gusmano, R. \& Ronco, C. (1998). Chronic renal replacement therapy in children: which index is best for adequacy? Kidney Int, Vol. 54, No. 5, pp. (1690-6)

Waikar, S. S. \& Bonventre, J. V. (2009). Creatinine kinetics and the definition of acute kidney injury. J Am Soc Nephrol, Vol. 20, No. 3, pp. (672-9)

Waniewski, J. (2006). Mathematical modeling of fluid and solute transport in hemodialysis and peritoneal dialysis. J. Membr. Sci., Vol. 274, pp. (24-37)

Waniewski, J., Debowska, M. \& Lindholm, B. (2006). Theoretical and numerical analysis of different adequacy indices for hemodialysis and peritoneal dialysis. Blood Purif, Vol. 24, No. 4, pp. (355-66)

Waniewski, J., Debowska, M. \& Lindholm, B. (2010). Can the diverse family of dialysis adequacy indices be understood as one integrated system? Blood Purif, Vol. 30, No. 4, pp. (257-65)

Waniewski, J. \& Lindholm, B. (2004). Fractional solute removal and KT/V in different modalities of renal replacement therapy. Blood Purif, Vol. 22, No. 4, pp. (367-76)

Waniewski, J., Werynski, A., Ahrenholz, P., Lucjanek, P., Judycki, W. \& Esther, G. (1991). Theoretical basis and experimental verification of the impact of ultrafiltration on dialyzer clearance. Artif Organs, Vol. 15, No. 2, pp. (70-7)

Werynski, A. \& Waniewski, J. (1995). Theoretical description of mass transport in medical membrane devices. Artif Organs, Vol. 19, No. 5, pp. (420-7)

Weryński, A. \& Nowosielcew, W. (1983). Kompartmentowe modelowanie procesów sterowania w systemach fizjologicznych Wydawnictwo Komunikacji i Łączności, 83-206-0284-X, Warszawa

Work Group (2001). I. NKF-K/DOQI Clinical Practice Guidelines for Hemodialysis Adequacy: update 2000. Am J Kidney Dis, Vol. 37, No. 1 Suppl 1, pp. (S7-S64)

Work Group (2002). Section II. Haemodialysis adequacy. Nephrol Dial Transplant, Vol. 17 Suppl 7, pp. (16-31)

Work Group (2006). Clinical practice guidelines for hemodialysis adequacy, update 2006. Am J Kidney Dis, Vol. 48 Suppl 1, pp. (S2-90)

Zaluska, W. T., Malecka, T., Swatowski, A. \& Ksiazek, A. (2002). Changes of extracellular volumes measured by whole and segmental bioimpedance analysis during hemodialysis in end-stage renal disease (ESRD) patients. Ann Univ Mariae Curie Sklodowska Med, Vol. 57, No. 2, pp. (337-41)

Ziolko, M., Pietrzyk, J. A. \& Grabska-Chrzastowska, J. (2000). Accuracy of hemodialysis modeling. Kidney Int, Vol. 57, No. 3, pp. (1152-63) 


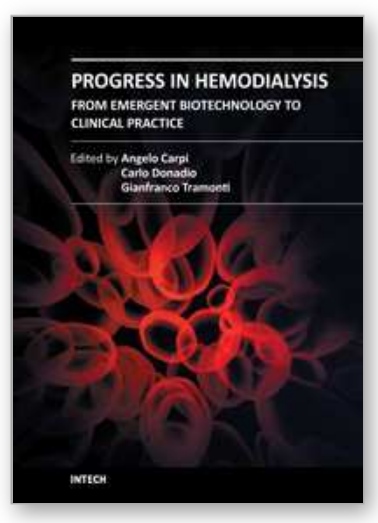

\section{Progress in Hemodialysis - From Emergent Biotechnology to Clinical Practice}

Edited by Prof. Angelo Carpi

ISBN 978-953-307-377-4

Hard cover, 444 pages

Publisher InTech

Published online 07, November, 2011

Published in print edition November, 2011

Hemodialysis (HD) represents the first successful long-term substitutive therapy with an artificial organ for severe failure of a vital organ. Because HD was started many decades ago, a book on HD may not appear to be up-to-date. Indeed, HD covers many basic and clinical aspects and this book reflects the rapid expansion of new and controversial aspects either in the biotechnological or in the clinical field. This book revises new technologies and therapeutic options to improve dialysis treatment of uremic patients. This book consists of three parts: modeling, methods and technique, prognosis and complications.

\section{How to reference}

In order to correctly reference this scholarly work, feel free to copy and paste the following:

Malgorzata Debowska, Bengt Lindholm and Jacek Waniewski (2011). Kinetic Modeling and Adequacy of Dialysis, Progress in Hemodialysis - From Emergent Biotechnology to Clinical Practice, Prof. Angelo Carpi (Ed.), ISBN: 978-953-307-377-4, InTech, Available from: http://www.intechopen.com/books/progress-inhemodialysis-from-emergent-biotechnology-to-clinical-practice/kinetic-modeling-and-adequacy-of-dialysis

\section{INTECH}

open science | open minds

\section{InTech Europe}

University Campus STeP Ri

Slavka Krautzeka 83/A

51000 Rijeka, Croatia

Phone: +385 (51) 770447

Fax: +385 (51) 686166

www.intechopen.com

\section{InTech China}

Unit 405, Office Block, Hotel Equatorial Shanghai

No.65, Yan An Road (West), Shanghai, 200040, China

中国上海市延安西路65号上海国际贵都大饭店办公楼 405 单元

Phone: +86-21-62489820

Fax: +86-21-62489821 
(C) 2011 The Author(s). Licensee IntechOpen. This is an open access article distributed under the terms of the Creative Commons Attribution 3.0 License, which permits unrestricted use, distribution, and reproduction in any medium, provided the original work is properly cited. 